\title{
Analysis of service selling and design for remanufacturing
}

\author{
Erik Sundin, Nicholas Jacobsson and Mats Björkman
}

\section{Linköping University Post Print}

\section{Tweet}

N.B.: When citing this work, cite the original article.

(c) 2000 IEEE. Personal use of this material is permitted. Permission from IEEE must be obtained for all other users, including reprinting/ republishing this material for advertising or promotional purposes, creating new collective works for resale or redistribution to servers or lists, or reuse of any copyrighted components of this work in other works.

Original Publication:

Erik Sundin, Nicholas Jacobsson and Mats Björkman, Analysis of service selling and design for remanufacturing, 2000, Proceedings of the 2000 IEEE International Symposium on Electronics and the Environment, 2000. ISBN: 0-7803-5962-3

http://dx.doi.org/10.1109/ISEE.2000.857661

From the IEEE International Symposium on Electronics and the Environment (IEEE-00), San Francisco, CA, USA, 8-10 May

Postprint available at: Linköping University Electronic Press http://urn.kb.se/resolve?urn=urn:nbn:se:liu:diva-13535 


\title{
ANALYSIS OF SERVICE SELLING AND DESIGN FOR REMANUFACTURING
}

\author{
Erik Sundin ${ }^{1}$, Mats Björkman ${ }^{1}$ and Nicholas Jacobsson ${ }^{2}$ \\ ${ }^{1}$ Department of Mechanical Engineering, Division of Production Systems \\ Linköpings Universitet, S-581 83 Linköping, Sweden \\ ${ }^{2}$ International Institute for Industrial Environmental Economics, \\ Lund University, Tegnérsplatsen 4, P.O. Box 196, 22100 Lund, Sweden
}

\begin{abstract}
A focus on selling services or functions instead of physical products can, through remanufacturing, be a way of closing material flows in present society. When a company decides to sell services, a closer connection with the customer can be established and a better control over the products can be achieved. This analysis shows that it is preferable that products aimed for service selling are designed for remanufacturing, since this facilitates the remanufacturing. With remanufacturing, economical and environmental benefits can be gained. Historical cases indicate this, and are described in this article along with an ongoing pilot project of service selling.
\end{abstract}

\section{Introduction}

The present rate of extraction of material from the earth's crust is not sustainable. It is not only the decrease of resources, but also the waste problems that are related to the extraction that are unsustainable. In order to reach a sustainable development (i.e. a development that meets the needs of the present without compromising the ability of future generations to meet their own need [1]) mankind needs, to a larger extent, close these unsatisfying material flows. This can be accomplished by a larger degree of product recovery, e.g. material recycling and product remanufacturing. A means of closing the flows is to focus on selling services or functions instead of physical products; the condition is that the hardware used in association with the service is remanufactured. Moreover, the production and processing of raw material are decreased when the hardware is remanufactured.

There is an emerging trend for some manufacturing industries to strive more and more towards selling services rather than just physical products. The service products are often comprised of one service part and one hardware part, the physical product.
This change of focus from traditional marketing and manufacturing of physical products is a way for the company to increase the value of the total product. Hence, the company's part of the total value chain increases. The concept of selling or providing services now enters more classical manufacturing industries, for example the white goods industry.

This article will describe the concepts of service selling and remanufacturing. Moreover, it will describe their interrelation and benefits from the industrial as well as the social perspectives. Finally, a brief explanation of where and how to implement these considerations into product development will be presented.

The input for this article was gathered from literature in the research area of remanufacturing and product development. Interviews with people from industry were also conducted to provide additional information.

\section{Selling services}

The essential idea of selling services is to focus more on how to satisfy the customer's need rather than on a physical product that may satisfy this need. The service-providing company may satisfy customer needs by providing hardware in the form of physical products. This generally means that the physical product that performs the service is owned by the service-providing company and not by the customer. By doing this, the customers only pay for the actual function that the physical product provides. An agreement is signed between the customer and the service-providing company concerning in what manner the service will be provided. The agreement states how often maintenance, etc. will be performed on the physical product during the service-providing period. The customer payment can include several different parts: 
- The service providing performed by the physical product.

- The maintenance and repair of the physical product.

- The upgrading and modernisation of the physical product.

Companies that are selling services have the opportunity to get a closer connection to their customers in comparison to the concept of classical product selling at ordinary stores. This close connection between customer and service-providing companies will also give the company the opportunity to sell several services at the same time. For example, a company like the Swedish white goods manufacturer 'Electrolux' could sell the service to utilise a fully equipped kitchen with all the features the customer desires. At present, the refrigerator in an ordinary kitchen might have the brand of 'Electrolux', the microwave oven 'Whirlpool', the coffee machine 'Braun' etc. If the service selling company provides the service to the customer's satisfaction, it is likely that the customer will turn to the same company for more service providing in the future.

\section{Remanufacturing}

Within the area of environmental research, it is important to elucidate the various concepts, which are used. These often cause confusion for readers, who have different backgrounds and use different definitions for the concepts of remanufacturing, recycling, reuse etc. Fig. 1 below illustrates where the remanufacturing phase is situated in the product life cycle and the relationships between the end-of-life options for the product. Allowing for materials recycling but giving highest priority to reuse, remanufacturing adds to the benefits of materials recycling by conserving as much of the original product identity as possible.
In the literature, there exist many definitions of remanufacturing [2, 3, 4, 5]. Most of them are variations of the same basic idea. The following definition is a synthesis of definitions from the references above, which is used in this article:

\section{Remanufacturing is the process of rebuilding a} product. During this process the product is cleaned, inspected and disassembled; defective components are replaced; and the product is reassembled, tested and inspected again to ensure it meets or exceeds newly manufactured product standards or even better.

The manufacturing process steps could be in different order, or some steps even omitted, at different remanufacturing plants depending on which products are to be remanufactured and at what volumes. For instance, it might in some cases be efficient to clean and disassemble the product before searching for defective parts. This could make sense when there is a large volume of products that are to be remanufactured with automatic disassembly lines. At lower volumes, it might be better to clean and test the product and only disassemble the defected parts.

\section{Possible benefits of remanufacturing service selling products}

\begin{abstract}
A. Societal benefits
With the remanufacture of products, less reprocessing is necessary and more energy, labour and capital equipment associated with primary production is recaptured than for materials recycling. While conventional materials recycling results in savings of processes and materials handling associated with production of crude, pure materials, remanufacturing provides further savings. Every time a part is reused, the energy and emissions that were produced in its manufacturing and the processing of its materials are salvaged [6].
\end{abstract}

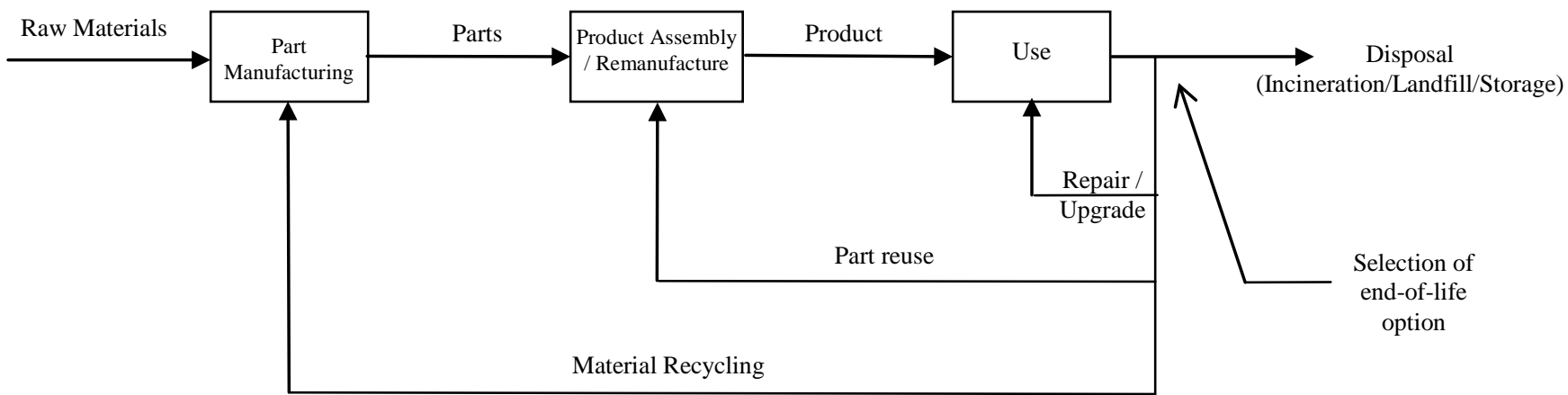

Fig. 1: Life of products. 
From a customer point of view, the concept of service selling may allow the choice of when to upgrade the physical product with new functions or colours as technology and fashion changes. Through service selling, customers do not need to make a large investment when buying a new product. The investments are more spread out, and there is no need to save money for unexpected repair. Moreover, people that are buying services instead of physical products achieve the possibility of a more flexible lifestyle. This is due to the fact that people do not need to buy new products when moving to a new location or apartment. The concept would be favourable for people who work in short-term projects at different locations.

Due to the level of disassembly and the necessary level of caution required in remanufacturing processes, remanufacturing is a rather labour intensive operation compared to many other recovery strategies, where one may shred the product in order to only recover the material. This might be considered a societal benefit of remanufacturing, since it is related to increased competition and the creation of jobs. Since remanufacturing reduces the need for virgin material, it may be argued that there will be a decrease in labour at the original suppliers of 'virgin' components. This might be true to a certain extent, but it has been shown that reduction in virgin material consumption results in an increase of manual labour in a remanufacturing system and that the total effect is increased labour intensity [7].

\section{B. Company benefits}

The closer contact between the manufacturer and the customer may enhance the interaction and relation between them. Increased control and monitoring of the physical products could be achieved through regular service and upgrading. This could also be achieved by information technology, like supervision and monitoring by means of Internet. Monitoring the product for the purpose of service selling/remanufacturing also allows the company to learn more about how it performs throughout its life. When the product is returned to the manufacturer for remanufacturing, it is possible to evaluate how the product has performed throughout its life and what needs to be improved. This knowledge allows the manufacturer to improve its products accordingly, reducing the need for service throughout the user phase.

Various perspectives can be applied concerning the length of the physical product lifetime compared to the classical product selling case. This is due to the fact that if the physical product lasts longer, more money can be earned and less material used in manufacturing to provide the selling service. The concept of total lifetime cost is more familiar for companies, such as, for example, service providers, than ordinary consumers. The consumers often strive to reduce the investment cost, not the total lifetime cost. Consumer products are normally designed with this perspective. When a company decides to focus on selling services instead of physical products, it's products should be designed regarding total lifetime cost instead of investment cost for the customer. Therefore, the physical products should also be designed for optimal remanufacturing benefits. Remanufacturing implies reusing at part level, and not material recycling according to Fig. 1. Product part reuse, as opposed to material recycling, would be a more environmental and economical means of product recovery. With product part reuse, most of the material processing and use of manufacturing resources (time, energy, costs etc.) required to produce new products are avoided [6, 8, 9, 10]. One should not forget that since remanufacturing creates more jobs, labour costs for the company are increased.

A remanufactured product could be restored to original specifications or be modernized and upgraded to new specifications. Hence, remanufacturing would not only promote the multiple reuse of materials, but it would also allow the upgrade of quality and functions of products steadily, without manufacturing completely new products and discarding used ones.

A frequent referred example of remanufacturing is the remanufacturing of Xerox photocopiers. Unfortunately, most of the reports on the environmental benefits of the Xerox remanufacturing operations are rather fragmented and do not present the issue from a full life cycle perspective. However, according to the most comprehensive study on the issue the environmental benefits generated by the remanufacturing operations are rather impressive [11]. For the Xerox model DC 265, which has been designed for remanufacturing (as opposite to the Xerox model 5100), the savings of energy equal a factor of 3.1 and those of materials and landfill waste a factor of 1.9. This is illustrated i Fig. 2.

It is important to note that these figures only represent the savings in resource productivity during the manufacturing and disposal phases. As photocopiers are energy and resource intensive during the user phase, this is where the majority of the environmental burden is generated. Consequently, when aggregating the environmental performance of remanufacturing with those generated during the user phase, the savings, in percentage, of remanufacturing 
are less than if only the manufacturing phase would be considered. Although this indicate that total life cycle savings of remanufacturing may be less for products with high energy intensity during its user phase one cannot neglect the staggering benefits. From a resource productivity point of view, remanufacturing still produce benefits whatever the energy intensity is during the user phase.

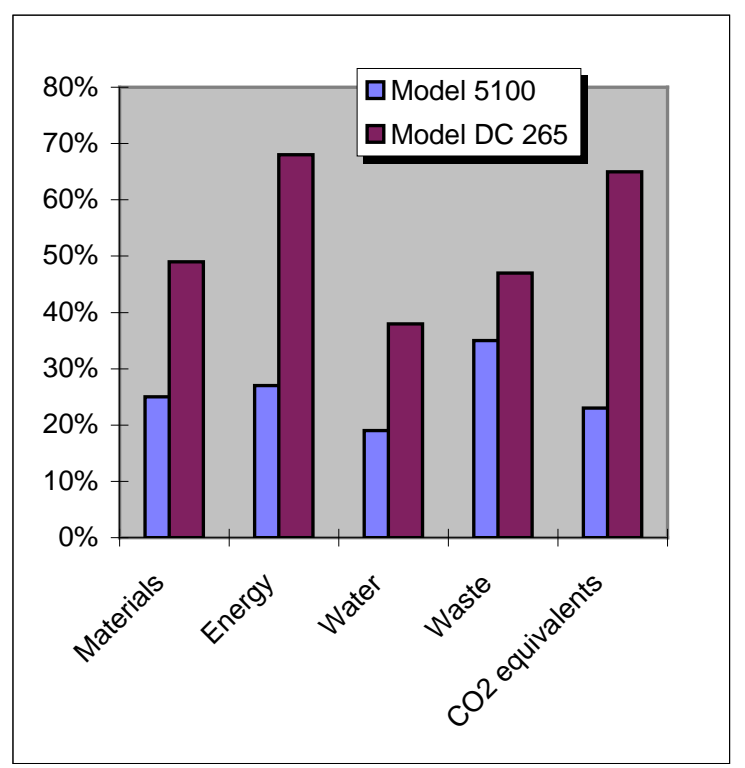

Fig. 2: Environmental savings in Remanufacturing vs. manufacturing Xerox photocopiers, model 5100 and DC 265[11].

\section{Product development}

The development of new products commonly follows a similar sequence as shown in Fig. 3. It is important to put much effort into the first phases in product development process, i.e. phase 0 and 1 in Fig. 3, since costs increase if product specification changes are made later in the process. Thus, the expression 'do things right from the beginning' is valid. Since the service selling and remanufacturing aspects should be considered already in the early stages of the product development process, this often demands additions to the traditional product development process. For instance, remanufacturing aspects should be integrated in the table of the product's customer needs or be appended to the engineering specification list. The engineering specification list specifies with metrics how the customer needs will be fulfilled with a target value and adherent limits. These aspects could either be derived from product users or through other internal company demands. According to Amezquita and Bras [5], the most effective way to boost remanufacturing is with an integrated product and process design approach, i.e. concurrent engineering.

In the central phases of the product development process, the design team focuses on how to design the product. In these phases, design-for-X (DFX) methodologies are often used, where $\mathrm{X}$ can stand for environment, robustness, recycling, assembly, disassembly, manufacturing, remanufacturing, etc. In the past, much research has been conducted in the area of design for environment (DFE). The overall purpose of environmental conscious design, or DFE, is to reduce the total environmental load during a product life cycle meanwhile society needs still are provided [13]. Design for remanufacturing should be part of design for environment. Within design for remanufacturing, many aspects must be considered, such as ease of disassembly, sorting, cleaning, refurbishment, reassembly and testing. Facilitating product and part reuse is an essential goal in design for remanufacture. Naturally, it is possible to remanufacture products that are not designed for this purpose, still it is preferable to have them designed for remanufacture.

It may be argued that adapting a product for disassembly, cleaning or reassembly is meaningless if the product or it's parts are not intended to be reused [14]. This might not always be true since it could be very useful to adapt/design products for remanufacturing considering future take-back laws. These take-back laws would put pressure on the producers to have a certain percentage of manufactured products taken back.

\section{The Electrolux Case}

The Swedish household appliance company Electrolux is currently conducting a pilot service selling project in Sweden. The project is mainly driven by tangible economical reasons and facilitated

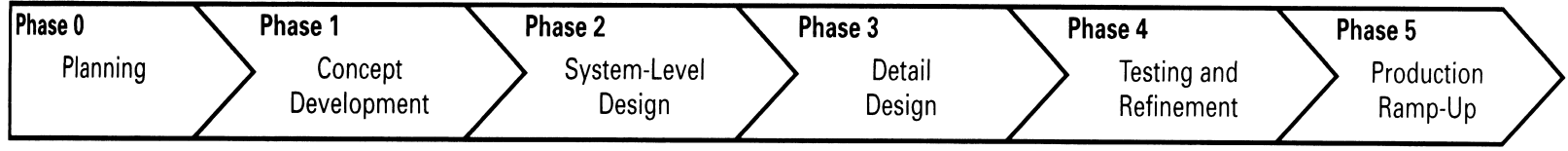

Fig. 3: The product development process [12]. 
through cooperation with the local energy provider. The service that is provided is laundry. Laundry is provided to 50 households, at a cost of $10 \mathrm{SEK} \approx 1.2$ USDs per laundry. The contracts are signed for 1000 washing cycles, but with a freedom for the consumer to terminate the agreement without any additional costs. After 1000 washes a new agreement is signed if there still is a demand for the service. In this pilot project, upgrading is not used or allowed but could be integrated, if there is a need for it. Moreover, Electrolux sells other white good services through another company. In this case, the other company makes the agreements with the customers and Electrolux is responsible for the maintenance service of the products. With these examples of service selling, Electrolux aims to achieve a closer connection with its consumers, but still co-operate with their retailers, and offering them a flexible alternative to ordinary product selling.

In relation to their service selling, Electrolux has a remanufacturing plant, also situated in Sweden. Currently, white goods like ovens, refrigerators, and freezers are remanufactured. The remanufacturing plant is situated within the same area as an ordinary manufacturing plant. This enables Electrolux to use the same logistics system for the remanufactured products as for the newly manufactured products. The remanufactured products are sold as Factory Reconditioned products through the normal market channels.

During remanufacturing, damaged parts are replaced with new or reused ones in order to restore the product to the same specifications as when new. The remanufactured products are products that have been returned for warranty reasons. These are two years old at maximum. An extension to the remanufacturing of older products is expected in the future. The following steps are made in the remanufacturing facility:

1. Testing.

2. Identifying errors.

3. Deciding how to recover the different parts.

4. Cleaning.

5. Checking with the product number to see if all required parts are present.

6. Disassembly.

7. Reassembly

8. High-voltage testing

9. Re-labelling the products as Factory Reconditioned

10. Final testing
This remanufacturing plant is only a project remanufacturing at small volumes, but it has the ability to grow if it is successful for Electrolux to remanufacture products.

\section{Discussion and conclusions}

Innovations may result in new technology that meets the same needs far better than previously manufactured products. Consequently, it is not necessary, from an environmental point of view, preferable to strive to extend the life of a product. This may result in a longer usage phase with obsolete technology. It is, therefore, preferable to optimise the life of a product rather than extending its life [15].

Remanufacturing may, therefore, not be environmentally suitable for all products. Products that have a high technology development rate are not as suitable as products that are more technically mature. Washing machines are mature enough to be remanufactured since technology has not changed that much over several years. If there is a small part of the product, which has a fast technology development, it could be structured as a module. This module could be placed within the product in such manner that it would be easy to replace and thus the product would be easier to remanufacture. It shall, however, be emphasised that remanufacturing is not direct reuse but an approach that aims to upgrade wherever suitable. However, it is important to note that upgrading during remanufacturing has proven possible for complex electrical products. If old technology can be replaced with new, e.g. replacing a product module, design for remanufacturing can be a means to reduce the problem of products becoming obsolete.

Although few exact figures have been published, a wide range of case studies support the profitability of remanufacturing. Also, no studies or material indicating that remanufacturing may effect the profit negatively have been found. Possible company costs increases are those derived from increased labour and logistics. Generally, examples proving the profitability provide the general profitability of the entire remanufacturing operation throughout a firm. Only one example has been found where the profitability is compared to another end-of-life options. The comparison indicated that remanufacturing indeed is a profitable alternative [16]. Finally, companies that are remanufacturing their products achieve an advantageous environmental profile in comparison to their market competitors.

This article has shown that companies, which are planning or have started selling services, should 
design their products with regard to remanufacturing. This is important since remanufacturing can be an essential part of or even a condition for economically and environmentally advantageous service selling. When the physical product is owned by the manufacturer, there are several benefits for reusing its parts and remanufacturing the product. Less material is needed for providing new services and less energy needed for the manufacture of parts and products than in the ordinary manufacture. Moreover, a better control over the physical products is achieved as well as a closer connection to the customer.

Customers are facilitated with a new option to choose a more flexible lifestyle. Society as a whole also benefits with increased remanufacturing, since the material flows are closed and more jobs may be created.

\section{Future research}

This research area is quite new and only a few articles have been published about service selling. The connection between service selling and remanufacturing must be further explored and evaluated. Moreover, a specification of which product properties are beneficial for service selling and remanufacturing ought to be identified and compared.

\section{Acknowledgements}

The authors wish to thank their contacts at Electrolux for sharing their information about their activities in this particular research area.

\section{References}

1. WCED, World Commission on Environment and Development, 1987, pp 43.

2. Seaver W.B., 'Design Considerations for remanufacturability, recyclability and reusability and reusability of user interface modules', IEEE international Symposium on Electronics and the Environment, San Francisco, CA, USA, 1994, pp 241-245.

3. APICS, http://207.87.14.34/sigs/reman/sig4req.htm\#What is remanufacturing? Website visited 1999-05-03, APICS - The Educational Society for Resource Management, 500 West Annandale Road, Falls Church, VA 22046-4274, USA.

4. Amezquita T. \& Bras B., 'Lean remanufacture of an Automobile clutch', Proceedings, First International Working Seminar on Reuse, Eindhoven, The Netherlands, 11-13 November, 1996, p6.

5. Bras B. \& Hammond R., 'Design for Remanufacturing metrics', Proceedings, First International Working Seminar on Reuse, Eindhoven, The Netherlands, 1113 November, 1996, p36.
6. Navin-Chandra D., 'Restar: A design tool for environmental recovery analysis', $9^{\text {th }}$ International Conference on Engineering Design, The Hague, Netherlands, 1993, pp. 780-787.

7. Ayres R., Ferrer G. \& Van Leynseele T., 'EcoEfficiency, Asset Recovery and Remanufacturing', Centre for the Management of Environmental Resources, INSEAD, Working Paper 97/35/TM, p9.

8. Amezquita T., Hammond R. \& Bras B., 'Characterizing the Remanufacturability of engineering systems’ 1995 ASME Advances in Design Automation Conference, DE-Vol. 82, Boston, Massachusetts, ASME, pp. 271-278.

9. Berko-Boateng V.J., Azar J., De Jong E., \& Yander G.A., 'Asset Recycle Management - A total approacgh to product design for the environment', IEEE, Arlington, VA, 1993, pp19-31.

10. Haynsworth H.C. \& Lyons R.T, 'Remanufacturing by design, the missing link', Production an inventory Management, Second quarter, 1987, pp. 25-28.

11. Kerr W. 'Remanufacturing and Eco-Efficiency: A case study of photocopier remanufacturing at Fuji Xerox Australia', M.S.c. Thesis, Environmental Management and Policy, International Institute for Industrial Environmental Economics (IIIEE), Lund University, 1999, pp. 56-68.

12. Ulrich K.T. \& Eppinger S.B., 'Product design and development', $2^{\text {nd }}$ Edition, McGraw-Hill, USA, 2000, ISBN 0-07-229647-X.

13. Ryding S. et Al, 'Miljöanpassad produktutveckling', Industriförbundet, Stockholm, Sweden, 1995, (in swedish).

14. Shu L.H. \& Flowers W.C., 'Considering Remanufacturing and other End-of-Life Options in Selection of Fastening and Joining Methods', IEEE International Symposium on Electronics and the Environment, Orlando, FL, USA, 1995, pp 75-80.

15. Jacqueline Cramer, Philips Consumer Electronics, 'Pros and Cons of Optimising the life of consumer electronic products', Proceedings, First International Working Seminar on Reuse, Eindhoven, The Netherlands, 11-13 November, 1996, pp74-84.

16. Ferrer, G. 'The Economics of PC Remanufacturing', Centre for the Management of Environmental Resources, INSEAD, Working Paper 97/37/TM, pp. 23-25 